\title{
Studies on dispersion and reactivity of vanadium oxides deposited on lamellar ferrierite zeolites for condensation of glycerol into bulky products
}

\author{
Luiz H. Vieira, Luiz G. Possato, Thiago F. Chaves, Sandra H. Pulcinelli, Celso V. Santilli, \\ Leandro Martins*
}

Instituto de Química, UNESP - Univ. Estadual Paulista, Rua Prof. Francisco Degni 55, CEP 14800-900, Araraquara, SP, Brazil

\section{A R T I C L E I N F O}

\section{Article history:}

Received 25 July 2017

Received in revised form 26 October 2017

Accepted 21 November 2017

Available online 1 December 2017

\section{Keywords:}

Glycerol condensation

Solketal

Vanadium

Lamellar zeolites

FER structure

\begin{abstract}
A B S T R A C T
The acetalization of acetone with glycerol was investigated using vanadium-impregnated catalysts. The siliceous supports FER, a purely microporous material, and ITQ-6, a micro/mesoporous material, were obtained from a ferrierite lamellar precursor, PreFER. Both supports were impregnated with 1,5 or $10 \mathrm{wt} . \%$ of vanadium. The structural properties were characterized by X-ray diffraction and $\mathrm{N}_{2}$ adsorption/desorption, the dispersion and speciation of surface vanadium were analyzed by diffuse reflectance UV-vis spectroscopy and X-ray absorption spectroscopy (XANES and EXAFS), and the total acidities of the catalysts were evaluated by temperature-programmed $\mathrm{NH}_{3}$ desorption. The [5V]Si-ITQ- 6 and [10V]SiITQ-6 catalysts provided the best catalytic results, with conversions of 100 and $90 \%$, respectively, and selectivity towards solketal of approximately $99 \%$. The higher surface area generated by mesoporosity in the Si-ITQ-6 support, compared to the microporous Si-FER support, provided good access for the diffusion of reactants and products, and good dispersion of vanadium, even at high vanadium loadings (10 wt.\%), with preferential formation of $\mathrm{VO}_{4}$ monomers and $\mathrm{VO}_{\mathrm{x}}$ oligomers on the surface. The greater contributions of these species to the total acidities of the catalysts resulted in higher catalytic activities, compared to the effect of $\mathrm{V}_{2} \mathrm{O}_{5}$ agglomerates.
\end{abstract}

(c) 2017 Elsevier B.V. All rights reserved.

\section{Introduction}

Massive amounts of cheap glycerol have become commercially available, due to its formation as a co-product in the biodiesel industry [1]. Biodiesel consists of fatty acid methyl esters that are normally obtained by transesterification of vegetable oils and methanol in the presence of an alkaline catalyst [2]. Approximately $10 \mathrm{wt} . \%$ of crude glycerol is generated during this process, and due to the growing interest in biodiesel as an alternative to fossil fuels, the production of 37 million metric tons is expected in 2020. Consequently, the amount of glycerol generated cannot be absorbed by traditional consumer industries, such as the cosmetics, pharmaceutical, and tobacco sectors, hence depressing its price and creating opportunities to find new applications for this compound [3]. Chemical transformations that are being explored in order to add value to glycerol include dehydration [4-9], oxidative

\footnotetext{
* Corresponding author.

E-mail address: leandro@iq.unesp.br (L. Martins).
}

dehydration [10-12], ammoxidation [13,14], hydrogenolysis [15-18], etherification [19-21], esterification [22,23], selective oxidation [24,25], and acetalization [26-29].

The acetalization of aldehydes and ketones with glycerol has been extensively studied using molecules such as formaldehyde [30], acetaldehyde [31], benzaldehyde [32], butyraldehyde [33,34], and acetone [35]. The acetalization of acetone with glycerol over acid catalysts (Scheme 1) can be used to produce cyclic acetals such as solketal. These compounds are especially interesting because their use as fuel additives reduces particulate emissions and improves the cold-flow properties [1,36]. The addition of $1-5$ vol.\% of solketal to gasoline has been found to significantly decrease gum formation caused by fuel degradation, while improving the octane number [37].

Conventionally, this reaction can be performed using heterogeneous or homogeneous catalysts, but for economic and environmental reasons, heterogeneous catalysts are normally preferred. Most studies of acetone acetalization using heterogeneous catalysts have focused on determining the effects of the molar ratio of reactants, catalyst loading, and time and temperature of the 


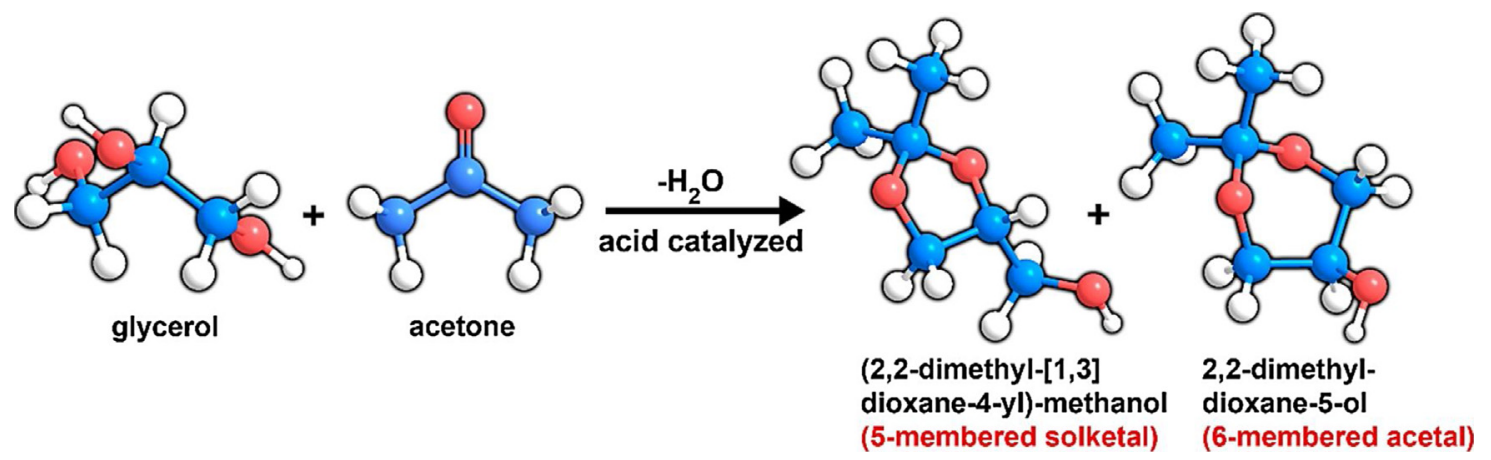

Scheme 1. Products obtained from acetalization of acetone with glycerol over acid catalysts.

reaction. Brønsted acid catalysts including zeolites [35], Amberlyst resins [35,38], and supported heteropolyacids [39] are commonly used, but good results have also been obtained using oxides of transition metals such as $\mathrm{Hf}$ and $\mathrm{Zr}$ supported on silica frameworks, which provide Lewis acid sites [40]. A promising transition metal for use in heterogeneous catalysis is vanadium, which has not yet been studied in this reaction. Vanadium-based catalysts have well known uses in oxidative processes such as oxidative dehydrogenation [41], oxidative dehydration [11], and selective oxidation reactions [42]. In addition to their use in oxidation reactions, this class of catalysts also exhibits moderate acidity, combining Lewis and weak Brønsted acid sites [43,44]. Essentially three types of vanadium oxide species can be found at the surfaces of the catalysts: monomeric $\mathrm{VO}_{4}$ and oligomeric $\mathrm{VO}_{\mathrm{x}}$ species, with tetrahedral coordination, and $\mathrm{V}_{2} \mathrm{O}_{5}$ crystallites. [45] The formation of these species is influenced by multiple factors including the synthesis and impregnation methods, the vanadium precursors employed, and the textural and chemical properties of the support.

The structural properties of the catalyst are critical in this reaction, since diffusion of the reactants and products at the catalyst in liquid phase reactions is favored by open-framework structures, where the active sites are more dispersed and are easily accessible. Catalysts based on zeolites offer good performance due to their high porosity and surface area. Ferrierite zeolites (FER structure) have shown remarkable catalytic performance in various processes. The discovery of the FER structure lamellar precursor called PreFER [46] has made it possible to develop different types of materials derived from this structure. Purely microporous FER zeolite can be obtained by direct calcination of the precursor, while the micro/mesoporous ITQ-6 zeolite is produced by expansion of the precursor layers with $\mathrm{CTABr}$, sonication, and calcination (Scheme 2). The mesoporosity in ITQ-6 is generated by spaces between disorganized layers. In addition to the higher surface area of this material, compared to other mesoporous materials such as MCM-41, it was found to be structurally more stable (the structure did not collapse), even after impregnation using high metal loadings [41].

In the present work, the silicalite forms of purely microporous (FER) and micro/mesoporous (ITQ-6) zeolites were synthesized using the same precursors and were employed as supports for vanadium oxide impregnation. The resulting catalysts were characterized by X-ray diffraction, nitrogen physisorption, diffuse reflectance UV-vis spectroscopy, X-ray absorption (XANES and EXAFS), and temperature-programmed desorption of ammonia. The catalysts were applied in acetone acetalization with glycerol. The preparation of these two supports with the same structure but with different porosity helped to understand the ways in which porosity influences the dispersion of vanadium at catalyst surfaces, as well as the diffusion of reagents and products to and from the active sites.

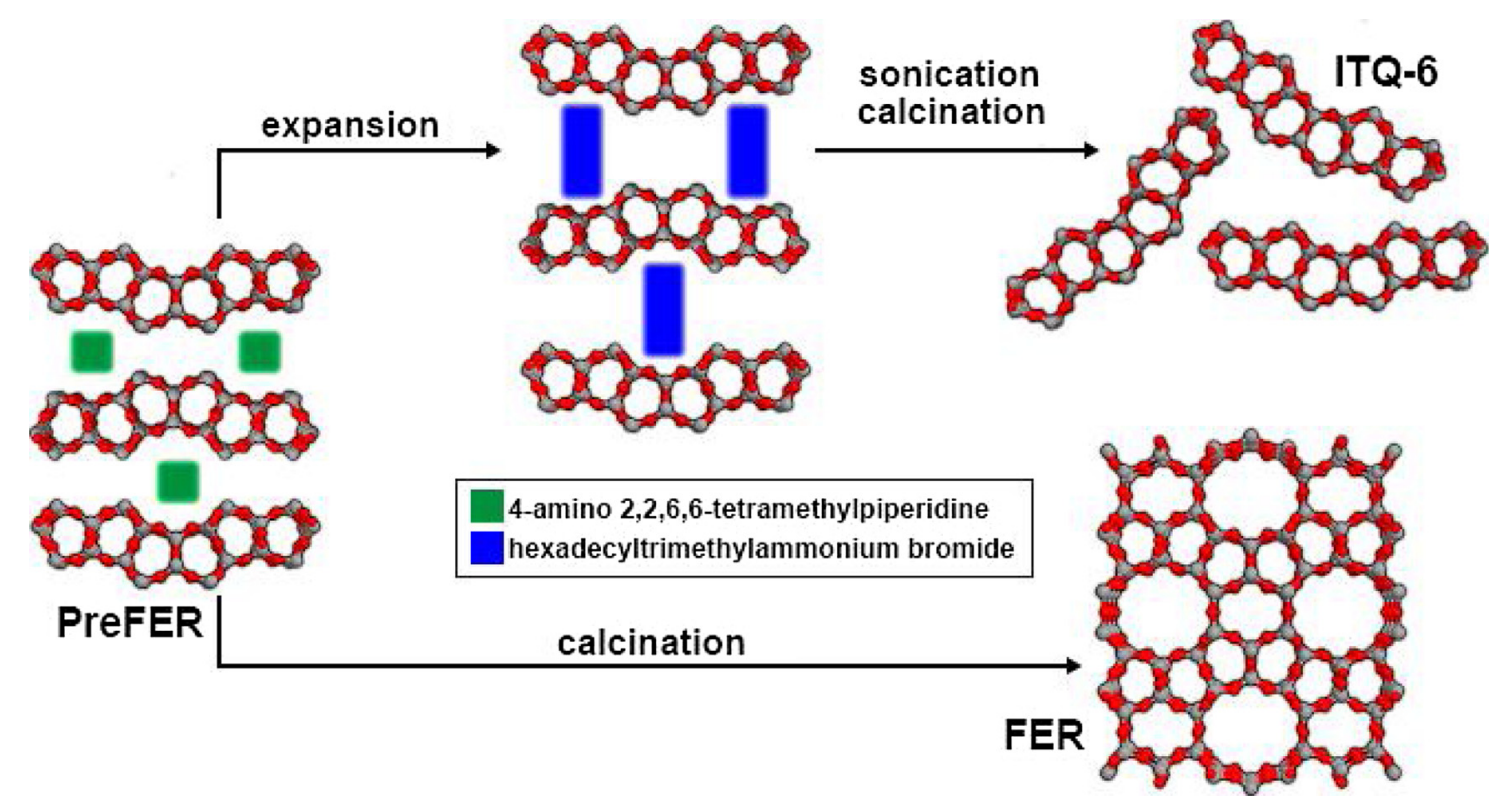

Scheme 2. Schematic representation of post-synthesis treatments, using the lamellar precursor PreFER. 


\section{Experimental section}

\subsection{Synthesis of the catalysts}

\subsubsection{Si-PreFER lamellar precursor}

An aqueous solution (22.9 g of distilled water) containing $7.5 \mathrm{~g}$ of ammonium fluoride, $1.0 \mathrm{~g}$ of hydrofluoric acid, $19.9 \mathrm{~g}$ of 4 -amino2,2,6,6-tetramethylpiperidine (R), and $7.7 \mathrm{~g}$ of fumed silica (molar composition: $25 \mathrm{SiO}_{2}$ : $10 \mathrm{HF}: 40 \mathrm{NH}_{4} \mathrm{~F}: 25 \mathrm{R}: 250 \mathrm{H}_{2} \mathrm{O}$ ) was prepared and stirred for $180 \mathrm{~min}$ at $30^{\circ} \mathrm{C}$, followed by heat treatment in a stainless steel autoclave for $120 \mathrm{~h}$ at $150{ }^{\circ} \mathrm{C}$. The solid product was filtered and washed with distilled water.

\subsubsection{Si-FER microporous support}

The microporous support was obtained by calcination of the lamellar precursor (Si-PreFER) in air for $6 \mathrm{~h}$ at $620^{\circ} \mathrm{C}$.

\subsubsection{Si-ITQ-6 micro/mesoporous support}

The micro/mesoporous support was obtained by refluxing a solution containing $190 \mathrm{~g}$ of distilled water, $10 \mathrm{~g}$ of Si-PreFER, $55 \mathrm{~g}$ of cetyltrimethylammonium bromide, and $120 \mathrm{~g}$ of tetrapropylammonium hydroxide $\left(20 \%\right.$ in $\left.\mathrm{H}_{2} \mathrm{O}\right)$ for $24 \mathrm{~h}$ at $80^{\circ} \mathrm{C}$. The solution was placed in an ultrasonic bath for $2 \mathrm{~h}$, and concentrated $\mathrm{HCl}$ was then added to the solution, until it reached $\mathrm{pH} 2$, in order to reprecipitate the layered material. The final precipitate was washed with distilled water, dried for $24 \mathrm{~h}$ at $80^{\circ} \mathrm{C}$, and calcined in air for $6 \mathrm{~h}$ at $620^{\circ} \mathrm{C}$.

\subsubsection{Vanadium oxide impregnation}

The $[n \mathrm{~V}] \mathrm{Si}$-FER and $[n \mathrm{~V}] \mathrm{Si}$-ITQ-6 catalysts (where $n$ stands for 1 , 5 , or $10 \mathrm{wt}$.\% of vanadium) were prepared by the wet impregnation method. Typically, $1 \mathrm{~g}$ of the support was added to a solution containing $50 \mathrm{~mL}$ of distilled water and vanadyl sulfate (the quantity of $\mathrm{VOSO}_{4}$ varied according to the final wt.\% of vanadium in the catalyst), followed by rotary evaporation at $60^{\circ} \mathrm{C}$ under vacuum until complete dryness. The samples were then calcined in air for $6 \mathrm{~h}$ at $500^{\circ} \mathrm{C}$.

\subsection{Characterization of the catalysts}

The crystalline phases of the zeolitic supports and impregnated catalysts were analyzed by X-ray diffraction at the XPD beamline of the Brazilian Synchrotron Light Laboratory (LNLS). The XPD beamline was equipped with a Huber $4+2$ circle diffractometer and a Eulerian cradle (model 513 ) positioned $\sim 13 \mathrm{~m}$ from a double-bounce $\mathrm{Si}$ (111) monochromator $(\lambda=1.377 \AA)$. The data were collected in high resolution mode, employing a $\mathrm{Si}(111)$ analyzer crystal and a Mythen detector. The measurements were performed at room temperature, in the $2 \theta$ range from 7 to $45^{\circ}$, with $8 \mathrm{~min}$ for each acquisition.

The textural characteristics of the catalysts were evaluated by means of nitrogen gas adsorption-desorption isotherms obtained at liquid nitrogen temperature $\left(\sim 196^{\circ} \mathrm{C}\right)$, with a relative pressure interval between 0.001 and 0.998 , using a Micromeritics ASAP 2010 instrument. Prior to the measurements, the samples were degassed under vacuum $\left(\sim 10 \times 10^{-6} \mathrm{~Pa}\right)$ for $12 \mathrm{~h}$ at $200^{\circ} \mathrm{C}$. The micropore area and volume were determined by the t-plot method, and the mesopore area and volume were determined by the BJH method.

The amounts of $\mathrm{V}$ present in the catalysts were determined by chemical analysis using an Optima 8000 ICP-OES spectrometer. Acid digestion was performed by suspending $100 \mathrm{mg}$ of sample in $1 \mathrm{~mL}$ of distilled water, followed by the addition of two drops ( $\sim=0.1 \mathrm{~mL}$ ) of concentrated sulfuric acid and $1 \mathrm{~mL}$ of $40 \mathrm{wt} . \%$ hydrofluoric acid. The suspension was heated to $100^{\circ} \mathrm{C}$ during $2 \mathrm{~h}$, and the resulting precipitate was diluted in $100 \mathrm{~mL}$ of deionized water.
Diffuse reflectance UV-vis spectra were obtained in the range from 190 to $800 \mathrm{~cm}^{-1}$, using a dual-beam PerkinElmer Lambda $1050 \mathrm{UV} / \mathrm{Vis} / \mathrm{NIR}$ spectrophotometer equipped with an integrating sphere. The reflectance was converted using the Kubelka-Munk equation and was plotted as a function of the wavelength.

X-ray absorption spectroscopy (XAS) measurements were recorded at the $\mathrm{V}$ K-edge, in transmission mode, at the XAFS1 beamline of LNLS. For vanadium analyses, the XAFS1 beamline was equipped with a $\mathrm{Si}(111)$ monochromator, operated in Bragg mode, for selection of the desired range of X-ray wavelengths. The monochromator was calibrated by setting the first inflection point at the K-edge spectrum of the corresponding metallic foil standard ( $5465 \mathrm{eV}$ for vanadium). The powdered samples, diluted with boron nitride, were presented in the form of pellets $(20 \mathrm{mg})$ whose thickness was chosen so that the normalized absorption jump at the edge was close to 1 . Analysis of the XAS data employed Athena graphical interface software, using three merged spectra to improve the signal-to-noise ratio. The references used for the spectra treatment were $\mathrm{V}_{2} \mathrm{O}_{4}, \mathrm{~V}_{2} \mathrm{O}_{5}$, and metallic vanadium foil.

Temperature-programmed desorption of ammonia ( $\left.\mathrm{NH}_{3}-\mathrm{TPD}\right)$ was used to quantify the acid sites present on the catalysts. The samples $(\sim 200 \mathrm{mg})$ were pretreated in a flow of helium $(60 \mathrm{~mL} / \mathrm{min})$ at $300^{\circ} \mathrm{C}$ for $1 \mathrm{~h}$, and were then cooled to $100^{\circ} \mathrm{C}$. Adsorption of $\mathrm{NH}_{3}$ was achieved by exposing the samples to a flow of $1 \% \mathrm{NH}_{3}$ in helium $(60 \mathrm{~mL} / \mathrm{min})$ for $1 \mathrm{~h}$, until saturation was reached. This was followed by flushing with helium $(60 \mathrm{~mL} / \mathrm{min})$ at $100{ }^{\circ} \mathrm{C}$ for $1 \mathrm{~h}$ to remove physisorbed $\mathrm{NH}_{3}$. Temperatureprogrammed desorption was performed from 100 to $550^{\circ} \mathrm{C}$, using a heating ramp of $10^{\circ} \mathrm{C} / \mathrm{min}$ and a helium flow of $60 \mathrm{~mL} / \mathrm{min}$. Quantification of the ammonia desorbed during heating was performed using a Pfeiffer PrismaPlus QMG 220 mass spectrometer.

\subsection{Catalytic tests}

The catalysts were evaluated in glycerol condensation with acetone using a 1:3 molar ratio (excess of acetone is necessary because it also plays the role of solvent in the reaction). The reactions were performed at $60^{\circ} \mathrm{C}$ for $120 \mathrm{~min}$. For each reaction, vials were filled with $0.4 \mathrm{~g}$ of glycerol, $2 \mathrm{~mL}$ of acetone, and $0.02 \mathrm{~g}$ of catalyst, and were kept under stirring in a water bath at $60^{\circ} \mathrm{C}$ for 10 , $20,30,60$, and $120 \mathrm{~min}$. After reaction, the vials were refrigerated at $0{ }^{\circ} \mathrm{C}$ and the catalyst was separated by filtration. The glycerol conversion and product selectivity were determined using a gas chromatograph (Shimadzu GC-2014) equipped with a capillary column (Rtx-1, $30 \mathrm{~m}, 0.32 \mathrm{~mm}, 1 \mu \mathrm{m}$ ) and an FID detector. Before each injection, a known mass of $n$-butanol was added as an internal standard in order to ensure a quantitative mass balance of glycerol and the products. The glycerol conversion $\left(\mathrm{X}_{\mathrm{gl}}\right)$ and products selectivity $\left(\mathrm{S}_{\mathrm{i}}\right)$ were calculated according to Eq. (1) and (2), respectively.

$$
\begin{aligned}
& X_{g l}(\%)=\frac{n_{g l 0}-n_{g l}}{n_{g l 0}} \times 100 \\
& S_{i}(\%)=\frac{n_{i}}{n_{g l 0}-n_{g l}} \times 100
\end{aligned}
$$

where $n_{\mathrm{gl0}}$ and $\mathrm{n}_{\mathrm{gl}}$ are the mole of glycerol in the beginning and in the end of the reaction, $n_{i}$ is the mole of product $i$. In order to compare the catalytic efficiency of the materials and support our statements about the role of dispersed vanadium in the reaction, samples of Si-FER and Si-ITQ-6 supports, $\mathrm{V}_{2} \mathrm{O}_{5}$ and commercial samples of $\mathrm{H}$-Beta $(\mathrm{Si} / \mathrm{Al}=12.5)$ and $\mathrm{H}-\mathrm{ZSM}-5(\mathrm{Si} / \mathrm{Al}=25)$ zeolites were tested in the same reaction conditions. 

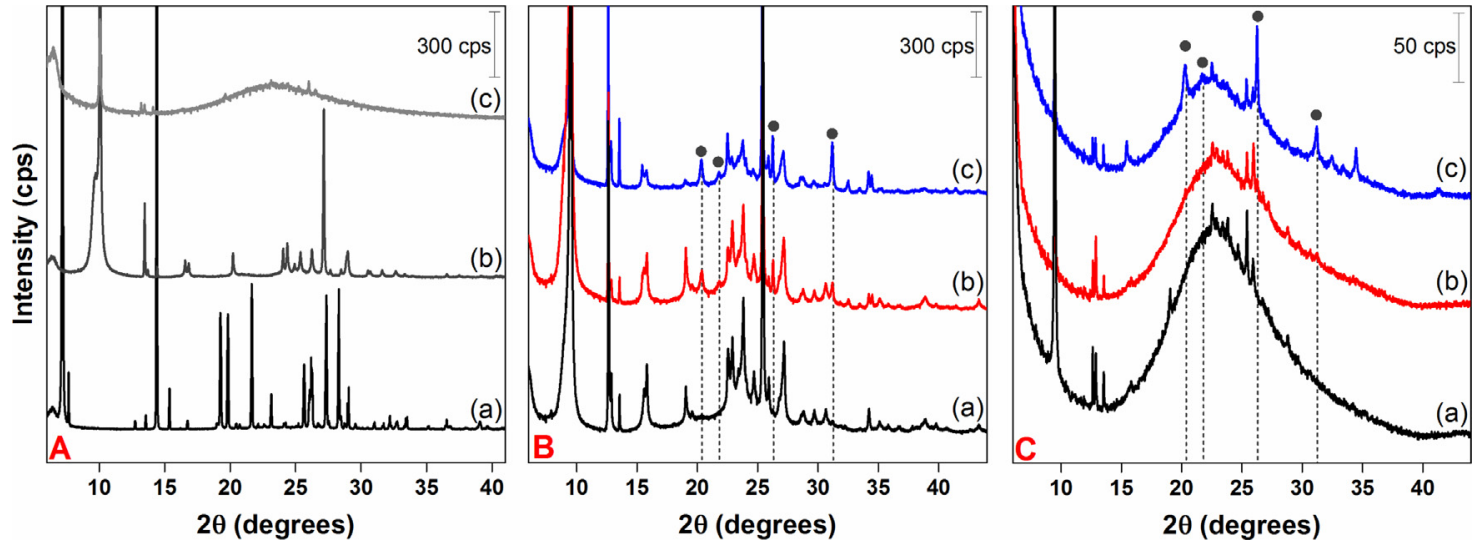

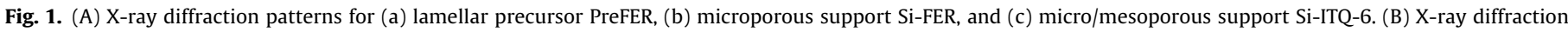

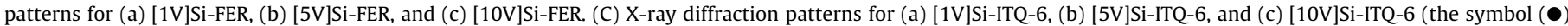
indicates the diffraction peaks of $\mathrm{V}_{2} \mathrm{O}_{5}$ phase).

\section{Results and discussion}

The X-ray diffraction patterns (Fig. 1A) confirmed formation of the crystalline structures of the lamellar precursor, Si-PreFER, and the microporous support, Si-FER [46]. During the process of exfoliation and formation of the micro/mesoporous support, Si-ITQ-6, the diffraction peak intensity was suppressed, due to the structural disorganization of the layers $[41,47]$. The X-ray diffraction patterns of the catalysts after vanadium impregnation of Si-FER (Fig. 1B) and Si-ITQ-6 (Fig. 1C) showed that the structures of the supports were maintained, even with $10 \mathrm{wt} . \%$ of vanadium loading. A high degree of dispersion was obtained for the [1V]Si-FER sample prepared using the microporous support (Si-FER), since no diffraction peaks of bulk vanadium oxide were detected. The diffractograms for the [5V]Si-FER and [10V]Si-FER samples showed the main diffraction peaks of $\mathrm{V}_{2} \mathrm{O}_{5}$ (Fig. S1), evidencing the formation of crystalline particles on the support surface. In the case of the samples obtained with the Si-ITQ-6 support, diffraction peaks related to the formation of crystalline $\mathrm{V}_{2} \mathrm{O}_{5}$ were only observed for the [10V]Si-ITQ-6 sample impregnated with $10 \mathrm{wt} . \%$ of vanadium. The X-ray diffraction results provided the first important evidence of the degree of dispersion in each catalyst, using these two different supports. These findings were supported by the results obtained with other techniques.

The textural properties of the catalysts were evaluated using nitrogen physisorption isotherms (Fig. 2A, Table 1). The SiFER-supported catalysts presented isotherms typical of purely microporous materials. The microporosity of these materials was generated by four different types of cavities in the structure composed of 5, 6, 8, and 10-membered rings (MR) [48]. After calcination, the 5-MR channels present in the layers of the lamellar precursor condensed, generating 6-MR and 10-MR channels perpendicular to the $a b$ plane, and 8-MR channels perpendicular to the ac plane (Scheme 3). There was a gradual decrease in the volume of micropores as the percentage of impregnated vanadium increased, as an indicative of the filling or blocking of the micropores by these species. In the case of the Si-ITQ-6-supported catalysts, the formation of mesopores was observed and the pore volume distribution (Fig. 2B) showed two main groups of pores, with average diameters of 2 and $15 \mathrm{~nm}$. The mesopore volume and surface area of these materials decreased as the percentage of impregnated vanadium increased, but the porosity remained high, even with impregnation
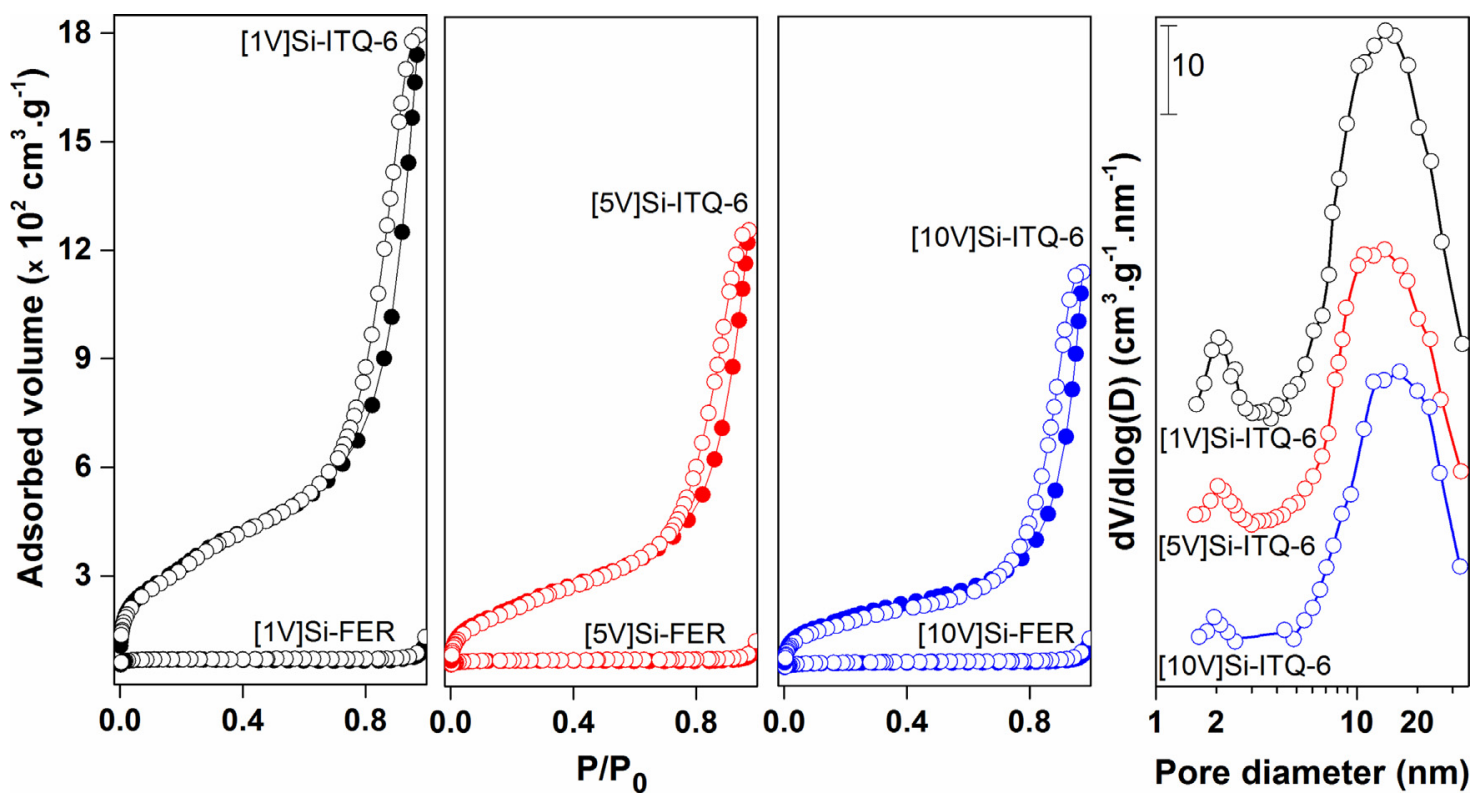

Fig. 2. Nitrogen physisorption isotherms for all the catalysts, and pore volume distribution (BJH desorption) for the Si-ITQ-6-supported catalysts. 
Table 1

Textural properties and total acidity of the catalysts.

\begin{tabular}{|c|c|c|c|c|c|c|}
\hline Catalyst & $\mathrm{V}(\mathrm{wt} . \%)^{\mathrm{a}}$ & $\mathrm{V}_{\text {micro }}\left(\mathrm{cm}^{3} \mathrm{~g}^{-1}\right)$ & $V_{\text {meso }}\left(\mathrm{cm}^{3} \mathrm{~g}^{-1}\right)$ & Surface area $\left(\mathrm{m}^{2} \mathrm{~g}^{-1}\right)^{\mathrm{b}}$ & Total acid sites $\left(\mu \mathrm{mol} \mathrm{NH}_{3} \mathrm{~g}^{-1}\right)$ & $\mathrm{mol} \mathrm{NH}_{3} / \mathrm{mol} \mathrm{V}$ \\
\hline [1V]Si-FER & 0.8 & 0.105 & 0.002 & $216(214)$ & 7.2 & 0.05 \\
\hline [5V]Si-FER & 4.5 & 0.103 & 0.006 & $228(214)$ & 116.3 & 0.13 \\
\hline [10V]Si-FER & 7.9 & 0.085 & 0.019 & 205 (177) & 75.7 & 0.05 \\
\hline [1V]Si-ITQ-6 & 1.0 & 0.030 & 1.904 & $1197(171)$ & 71.0 & 0.36 \\
\hline [5V]Si-ITQ-6 & 4.7 & 0.030 & 1.335 & $795(152)$ & 255.3 & 0.28 \\
\hline [10V]Si-ITQ-6 & 9.7 & 0.029 & 1.037 & $671(148)$ & 196.3 & 0.10 \\
\hline
\end{tabular}

a Determined by ICP-OES.

b Values in parentheses refer to the micropore area.
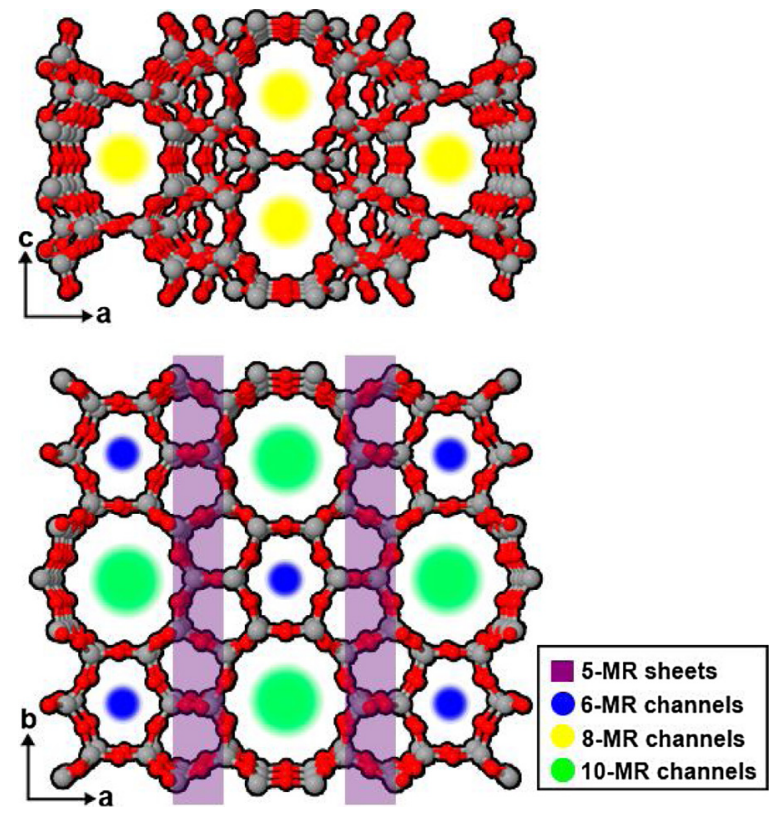

Scheme 3. Representation of different Si-FER channels.

at the highest percentage (sample [10V]Si-ITQ-6). Another important point is that microporosity was still present in these samples, associated with the presence of microporous cavities in each individual layer, confirming that the support structure did not collapse after the impregnation.

The dispersion of vanadium species formed on the surfaces of the materials was investigated using diffuse reflectance UV-vis and X-ray absorption spectroscopy. The DR-UV-vis spectra (Fig. 3) showed three different regions, corresponding to the formation of monomers ( $\sim 250-300 \mathrm{~nm})$ and oligomers $(\sim 350-400 \mathrm{~nm})$ of tetracoordinated vanadium, and agglomerates of pentacoordi- nated $\mathrm{V}_{2} \mathrm{O}_{5}(\sim 470-500 \mathrm{~nm})$. The wavelengths at which oxygen to $\mathrm{V}^{5+}$ charge transfer occurred in these species were determined based on previous studies of vanadium-supported materials reported in the literature [45]. The three Si-FER-supported catalysts (Fig. 3A) showed bands corresponding to the formation of isolated monomeric tetrahedrally-coordinated $\mathrm{VO}_{4}$ species, as well as oligomeric $\mathrm{VO}_{\mathrm{x}}$ species with distorted tetrahedral symmetry. Displacement of the band for oligomeric species was observed as the amount of impregnated vanadium increased, due to the formation of $\mathrm{V}_{2} \mathrm{O}_{5}$ agglomerates. In the case of the Si-ITQ-6-supported catalysts, a slight displacement of the $\mathrm{VO}_{\mathrm{x}}$ band was only observed for the [10V]Si-ITQ-6 sample. The $\mathrm{d}-\mathrm{d}$ charge transfer absorption bands characteristic of $\mathrm{VO}_{2}\left(\mathrm{~V}^{4+}\right)$, usually observed at higher wavelengths $\left(625 \mathrm{~nm}\right.$ for the $\mathrm{b}_{2}\left(\mathrm{~d}_{\mathrm{xy}}\right) \rightarrow \mathrm{b}_{1}\left(\mathrm{~d}_{\mathrm{x} 2-\mathrm{y} 2}\right)$ transition and $770 \mathrm{~nm}$ for the $b_{2}\left(d_{x y}\right) \rightarrow e\left(d_{x y}, d_{y z}\right)$ transition), were not present in the spectra of the catalysts, confirming that all the $\mathrm{V}^{4+}$ present in the precursor salt $\left(\mathrm{VOSO}_{4}\right)$ had been oxidized during calcination of the materials.

The X-ray absorption near vanadium K-edge spectroscopy (XANES region) results for the catalysts and $\mathrm{V}_{2} \mathrm{O}_{5}$ are shown in Fig. 4. In these materials, the pre-edge peak at around $5470 \mathrm{eV}$, due to $1 \mathrm{~s}$ to $3 \mathrm{~d}$ dipole-forbidden transitions, provides an indication of the degree of distortion of oxygen atoms in the first coordination sphere, which are affected by the degree of hybridization between the $2 p$ and $3 d$ orbitals $[49,50]$. When the degree of hybridization increases, the distance between the neighboring oxygen atoms becomes smaller and the pre-edge intensity increases. All the impregnated catalysts presented pre-edge intensities similar to that for the $\mathrm{V}_{2} \mathrm{O}_{5}$ sample. The oscillations after the absorption edge (starting at around $5485 \mathrm{eV}$ ) were related to the $1 \mathrm{~s}$ to $4 \mathrm{p}$ dipole-allowed transitions [50,51]. The intensity of these oscillations increased with the formation of crystalline vanadium oxide, as observed for the $\mathrm{V}_{2} \mathrm{O}_{5}$ sample. In the case of the Si-ITQ-6-supported catalysts, only the [10V]Si-ITQ-6 sample presented a subtle oscillation, reflecting the formation of small amounts of crystalline $\mathrm{V}_{2} \mathrm{O}_{5}$. The [5V]Si-FER, [10V]Si-FER, and $\mathrm{V}_{2} \mathrm{O}_{5}$ samples showed significant
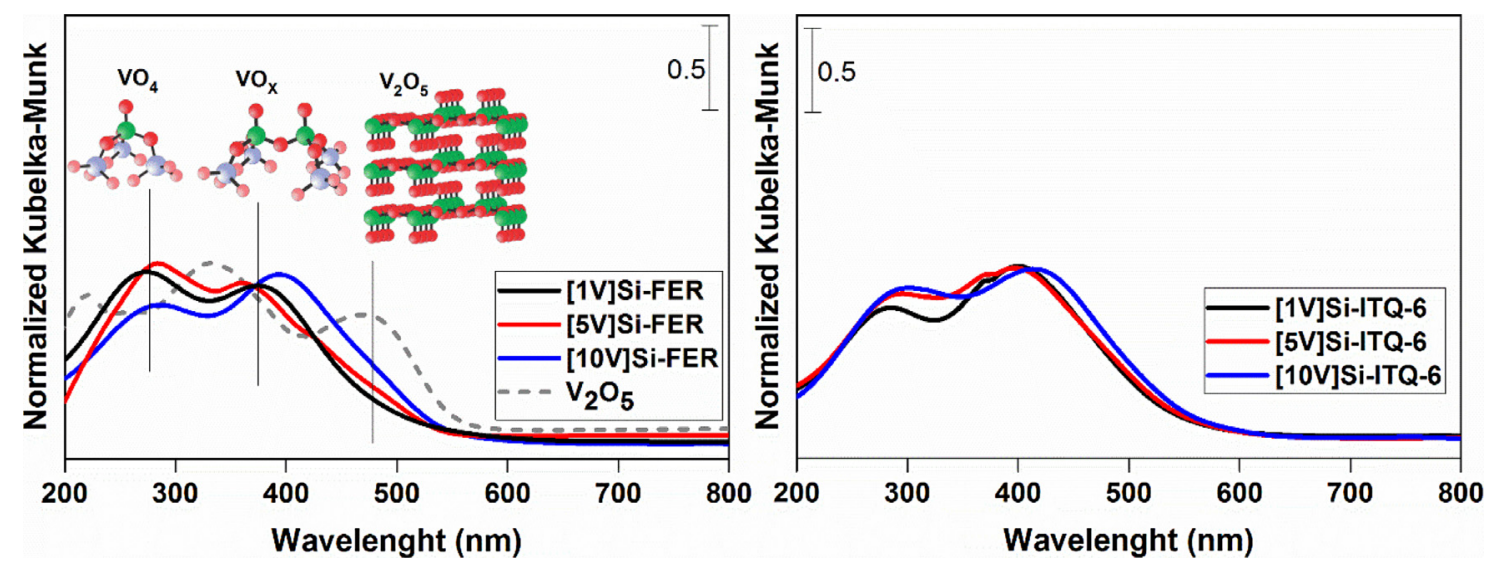

Fig. 3. Diffuse reflectance UV-vis spectroscopy analyses of the catalysts and $\mathrm{V}_{2} \mathrm{O}_{5}$ (reference). 


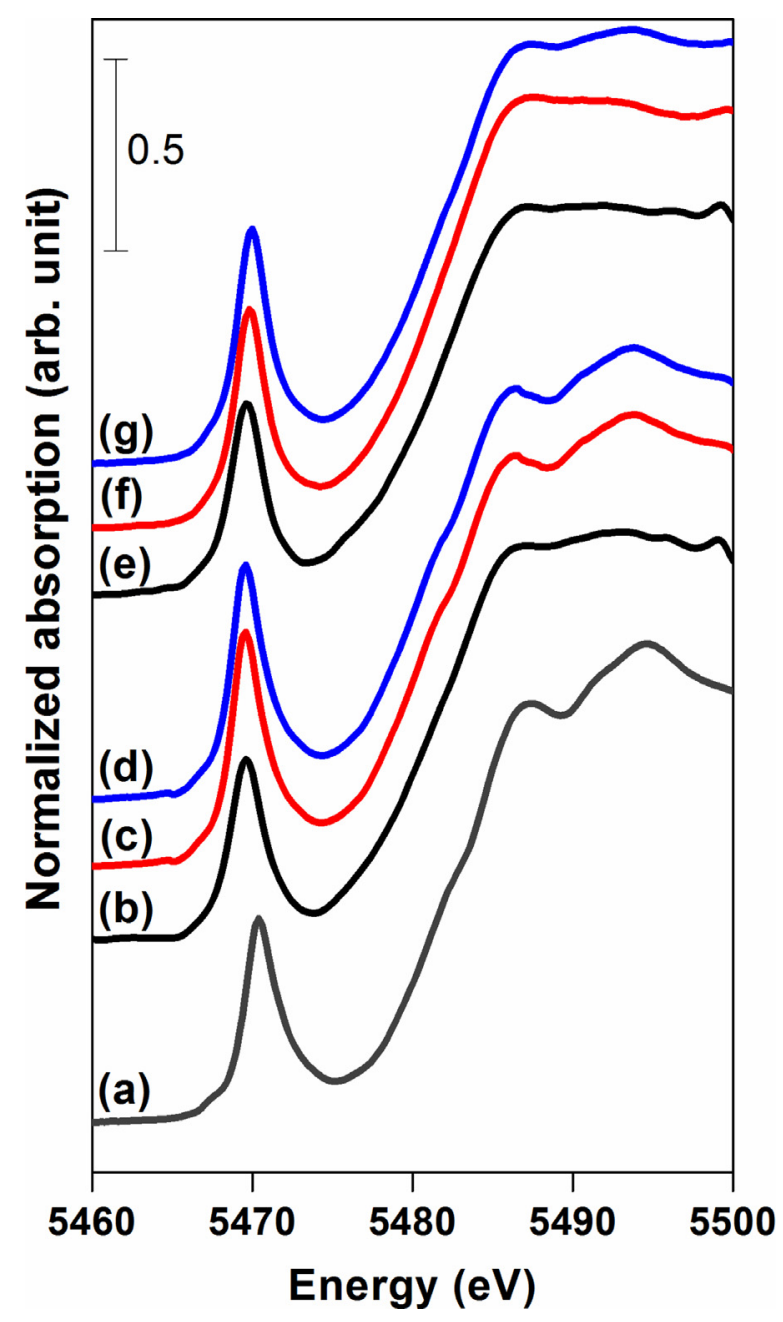

Fig. 4. X-ray absorption spectra (XAS) in the XANES region at the $\mathrm{V}$ K-edge for (a) $\mathrm{V}_{2} \mathrm{O}_{5}$, (b) [1V]Si-FER, (c) [5V]Si-FER, (d) [10V]Si-FER, (e) [1V]Si-ITQ-6, (f) [5V]Si-ITQ6 , and $(\mathrm{g})[10 \mathrm{~V}] \mathrm{Si}-\mathrm{ITQ}-6$.

congruency in the oscillations, suggesting the formation of considerable amounts of $\mathrm{V}_{2} \mathrm{O}_{5}$ agglomerates.

The EXAFS spectra of the impregnated catalysts and $\mathrm{V}_{2} \mathrm{O}_{5}$ (Fig. 5) showed different amplitudes of the oscillations, with the bulk vanadium oxide generally exhibiting greater amplitude, compared to the catalysts, reflecting a higher degree of disorder caused by dispersion on the surfaces of the materials. However, comparison of the EXAFS signals for the Si-FER and Si-ITQ-6 samples revealed considerable differences in the short-range order. For better visualization, the spectra were converted to $\mathrm{R}$ space using Fourier transform (Fig. 5). For $\mathrm{V}_{2} \mathrm{O}_{5}$, the first coordination sphere is composed of a vanadium atom pentacoordinated by oxygen, forming a distorted tetragonal pyramid, with the distances between the oxygen and vanadium atoms ranging from 1.58 to $2.02 \AA$. The distance for the atom at the apex of the pyramid is $1.58 \AA$, while the distances for the atoms at the base range from 1.78 to $2.02 \AA[50,52]$. The impregnated samples clearly showed lower intensity in this region of the spectrum, suggesting that a fraction of these bonds was absent, compared to the bulk $\mathrm{V}_{2} \mathrm{O}_{5}$, independent of the amount of vanadium dispersed on the support. This was probably due to the formation of tetrahedrally-coordinated $\mathrm{VO}_{4}$ and $\mathrm{VO}_{\mathrm{x}}$ species. Thus, gradual decreases in the signals corresponding to the first coordination sphere (1.78-2.02 $\AA$ ) for the Si-FER and Si-ITQ-6 catalysts compared to $\mathrm{V}_{2} \mathrm{O}_{5}$, reflected the formation of greater amounts of dispersed vanadium species on the surfaces.
From the evidence provided by the XRD, DR-UV-vis, and XAS analyses, it could be concluded that dispersed monomeric $\mathrm{VO}_{4}$ and oligomeric $\mathrm{VO}_{\mathrm{x}}$ species were present on all the supported catalysts, but that the supports had different effects on the dispersion of the oxides. When the microporous Si-FER material was used as a support, with a vanadium concentration of $5 \mathrm{wt} . \%$, considerable quantities of $\mathrm{V}_{2} \mathrm{O}_{5}$ agglomerates were found on the surface. In the case of the micro/mesoporous Si-ITQ-6 support, agglomeration of the vanadium oxides was only found for vanadium concentrations of $10 \mathrm{wt} . \%$.

The temperature-programmed $\mathrm{NH}_{3}$ desorption profiles for all the catalysts (Fig. 6) identified the presence of weak and intermediate acid sites, with complete desorption of ammonia occurring in the range $100-400^{\circ} \mathrm{C}$. For samples with the same percentage of vanadium, the Si-ITQ-6-supported catalysts possessed higher total numbers of acid sites, compared to the Si-FER-supported materials (Table 1 ). For both supports, higher acidity was found with $5 \%$ vanadium than with $10 \%$ vanadium. The nonlinear increase of total acid sites with increasing amounts of vanadium on the samples ( $\mathrm{mol} \mathrm{NH}_{3} / \mathrm{mol} \mathrm{V}$ in Table 1 ) was suggestive of differences in acidity among the species of vanadium present on the catalyst surfaces. In light of this finding, together with the information about the different vanadium species on the catalysts, provided by the DR-UV-vis (Fig. 3) and XAS (Fig. 4 and 5) analyses, it could be concluded that the increasing of the vanadium concentration and, consequently, the formation of more oligomeric species and $\mathrm{V}_{2} \mathrm{O}_{5}$ agglomerates are contributing to decrease the specific number of active sites.

The catalysts were used in the acetalization reaction, maintaining the same reaction conditions for all the catalysts. The glycerol conversions are shown in Fig. 7. The [1V]Si-FER and [1V]Si-ITQ6 samples showed conversions after 120 min of approximately 17 and $20 \%$, respectively. The very similar conversions obtained with these catalysts were expected, due to the high degrees of dispersion of vanadium on the surfaces of the two materials. The low conversions were related to the low vanadium loadings, because these catalysts showed good activities $\left(\mu \mathrm{mol}_{\text {glycerol }} / \mathrm{mol}_{\text {vanadium }} \cdot \mathrm{s}\right)$ when compared to the catalysts with higher vanadium loadings (Fig. 9). The [5V]Si-FER and [10V]Si-FER samples presented conversions of approximately 60 and 50\%, respectively, after $120 \mathrm{~min}$ of reaction. These catalysts showed clear negative effects of the formation of $\mathrm{V}_{2} \mathrm{O}_{5}$ agglomerates on the support, which considerably decreased the activity of these materials in the reaction (Fig. 9). A higher conversion after $120 \mathrm{~min}$ was achieved with the [5V]SiFER catalyst, despite a lower vanadium loading than [10V]Si-FER, which was probably due to the greater amounts of $\mathrm{VO}_{4}$ and $\mathrm{VO}_{\mathrm{X}}$ species remaining on this material. The [5V]Si-ITQ- 6 and $[10 \mathrm{~V}] \mathrm{Si}-$ ITQ-6 samples showed conversions of approximately 60 and $70 \%$, respectively, after only $10 \mathrm{~min}$ of reaction, with conversions after $120 \mathrm{~min}$ of 100 and $90 \%$, respectively. Comparison of the activities of these catalysts with those of the Si-FER support with the same vanadium loadings revealed the positive effect of dispersion of vanadium species in the mesopores of Si-ITQ-6. The [5V]Si-ITQ6 catalyst showed a higher conversion and better activity (Fig. 9) than [10V]Si-ITQ-6, probably due to the greater quantity of $\mathrm{V}_{2} \mathrm{O}_{5}$ agglomerates identified on the surface of [10V]Si-ITQ-6. Under the same conditions, reactions in the absence of catalyst (not shown), or using only the Si-FER and Si-ITQ-6 supports or bulk $\mathrm{V}_{2} \mathrm{O}_{5}$ (Table $\mathrm{S} 1$ ), resulted in negligible or very low glycerol conversions. To provide a benchmarking about the performance of our catalysts, two commercial zeolites in acidic form, H-Beta $(\mathrm{Si} / \mathrm{Al}=12.5)$ and $\mathrm{H}-\mathrm{ZSM}-5(\mathrm{Si} / \mathrm{Al}=25)$, were tested in the same reaction conditions (Table S1). Comparing the results [5V]Si-ITQ-6 and [10V]Si-ITQ-6 showed higher conversions, so we can conclude that the high acidity in H-Beta and H-ZSM-5 materials are being compromised by the presence of water, formed as the reaction evolves [35]. 

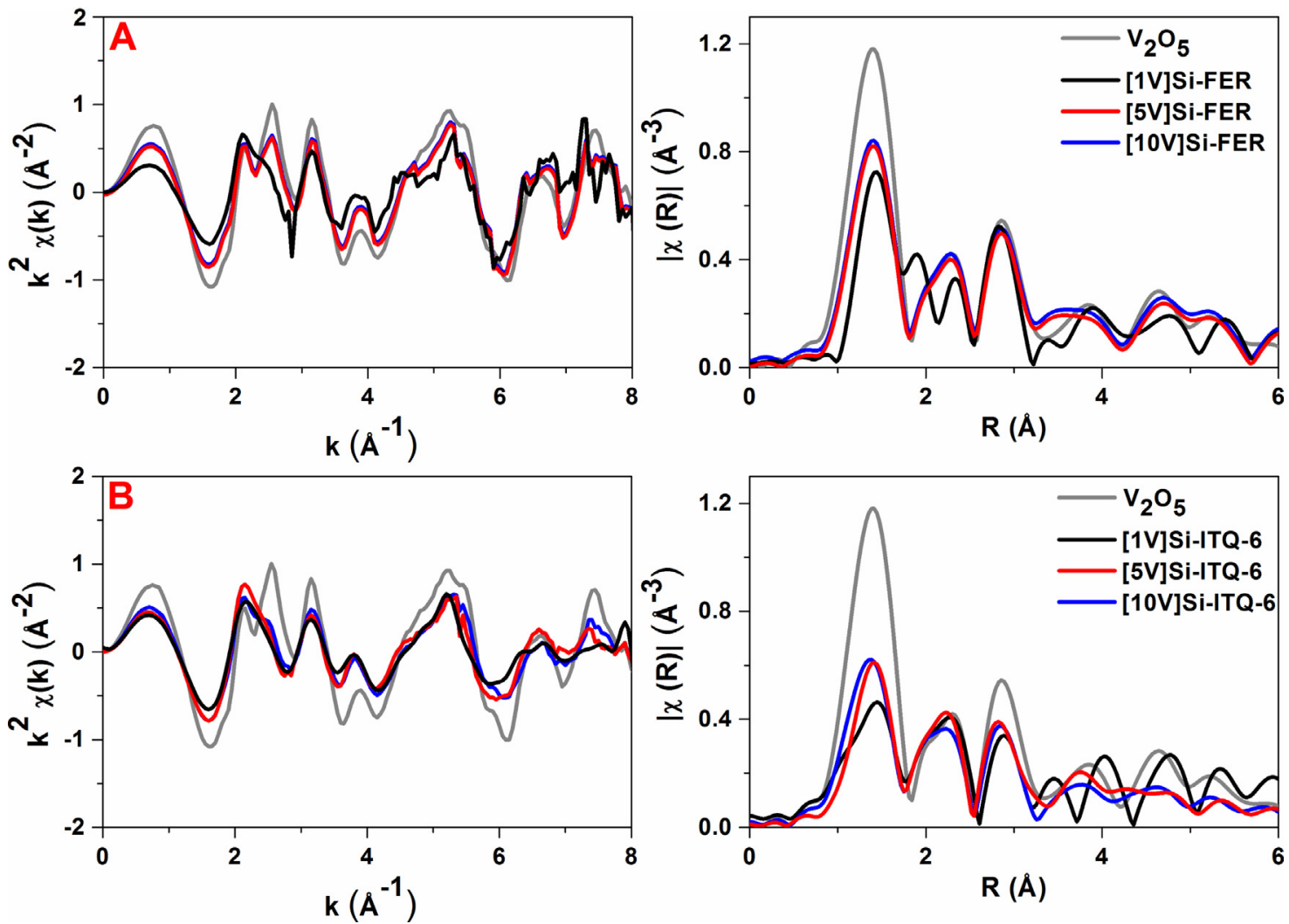

Fig. 5. EXAFS and Fourier transformed spectra for catalysts supported on (A) Si-FER and (B) Si-ITQ-6.

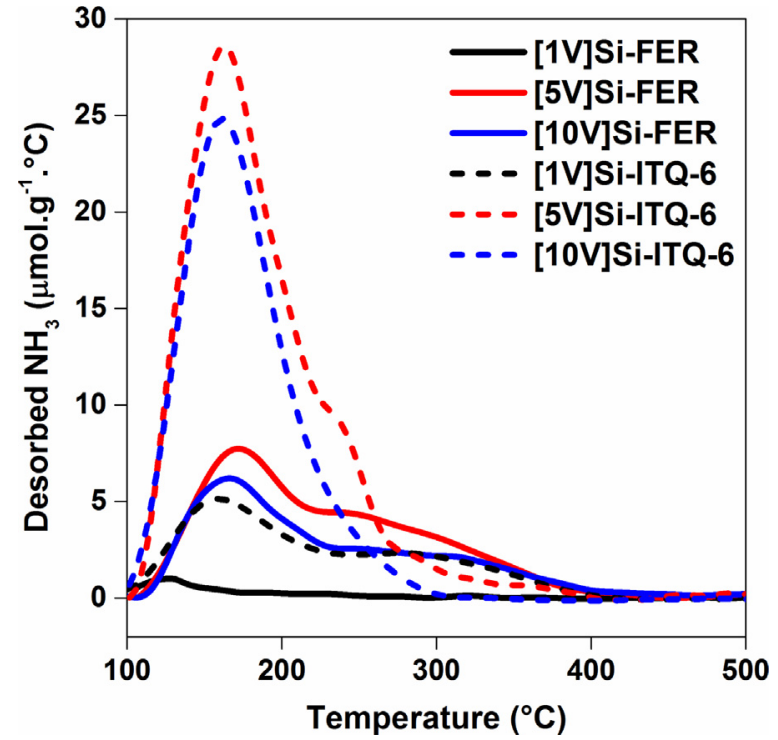

Fig. 6. Temperature-programmed $\mathrm{NH}_{3}$ desorption profiles of the catalysts.

The reaction led to the formation of the two products, solketal ((2,2-dimethyl-1,3-dioxolan-4-yl)-methanol) and a 6-membered ring acetal (2,2-dimethyl-dioxan-5-ol) (Fig. 8). According to the literature $[53,54]$, the formation of these compounds proceeds through a two-step mechanism, involving Lewis or Brønsted acid sites. In the first step, a tertiary alcohol is formed by interaction between the terminal hydroxyl group of glycerol and the carbonyl group of acetone. The second step involves the dehydration of the tertiary alcohol over the active site, forming a carbenium ion that can be rapidly attacked by the secondary hydroxyl group of glyc- erol, forming solketal, or by the terminal hydroxyl group of glycerol, forming the 6-membered ring acetal [53]. Due to the steric repulsions associated with the presence of axial methyl groups in the 6-membered ring acetal, theoretical calculations have suggested the preferential formation of solketal in this reaction [54]. In fact, most previous studies have identified solketal as the major product, as also found here. Using these catalysts, a trend could be observed according to which the formation of solketal was favored as the glycerol conversion increased, and for the [5V]Si-ITQ- 6 and [10V]Si-ITQ-6 catalysts, which achieved the highest conversions after 120 min, the selectivity towards this product was almost $100 \%$. The high number of dispersed sites in these catalysts probably favored the acid-catalyzed isomerization of the 6-membered ring acetal to form solketal [26].

The stability of catalyst [10V]Si-ITQ- 6 was evaluated by three consecutive runs in the same reaction conditions (Fig. 10). The catalyst was separated of reaction mixture after $1 \mathrm{~h}$ and washed using two different solvents: water (Fig. 10A) or acetone (Fig. 10B). Using water to wash the catalyst resulted in a completely loss of activity after the $3^{\text {rd }}$ run, probably associated with leaching of active vanadium species caused by the presence of water. In contrast, using acetone to wash the catalyst after each run a very low loss of activity is observed and, in this case, a moderate leaching of vanadium species are, probably, being caused by the water formed during reaction. Based on previous literature results and our observations during reaction a mechanism for condensation of glycerol with acetone over [V]Si-FER and [V]Si-ITQ-6 catalysts is proposed in Scheme 4. This mechanism suggests the adsorption of the intermediate tertiary alcohol in the vanadium. During reaction a change in color of catalyst, from dark yellow to green, is observed, that is probably associated with the changing in active site coordination caused by adsorption of the tertiary alcohol intermediate in the structure. After formation of solketal or 2,2-dimethyl dioxane- 

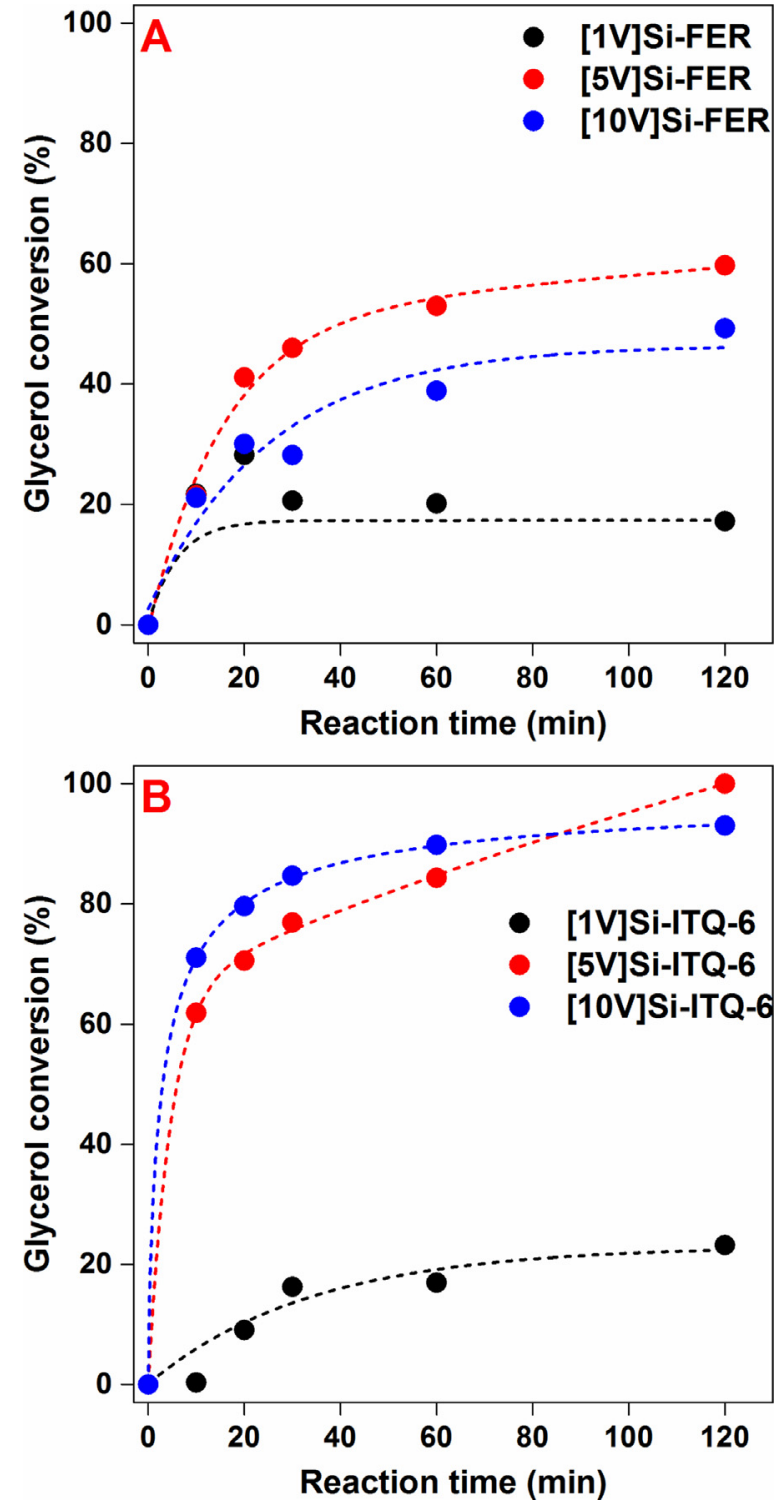

Fig. 7. Glycerol conversions using (A) the microporous vanadium catalysts and (B) the micro/mesoporous vanadium catalysts.

5-ol, the water molecule formed as a co-product probably keeps adsorbed in the surface of catalyst and, the increasing in the number of water molecules formed by consecutive adsorption in a same site are leading to vanadium leaching.

\section{Conclusions}

The lamellar precursor Si-PreFER and the supports Si-FER and Si-ITQ-6 were successfully synthesized. After impregnation, the supports showed high structural stability, even with high vanadium loadings. Three main vanadium species were identified on the catalyst surfaces: $\mathrm{VO}_{4}$ monomers, $\mathrm{VO}_{\mathrm{x}}$ oligomers, and $\mathrm{V}_{2} \mathrm{O}_{5}$ agglomerates. When Si-FER was used as the support, the formation of $\mathrm{V}_{2} \mathrm{O}_{5}$ agglomerates was observed on the [5V]Si-FER sample, while the Si-ITQ-6 support only showed the presence of $\mathrm{V}_{2} \mathrm{O}_{5}$ on the [10V]Si-ITQ-6 sample. The predominance of $\mathrm{VO}_{4}$ and $\mathrm{VO}_{\mathrm{x}}$ species on the surface of the micro/mesoporous Si-ITQ-6 support contributed to higher total acidity of the catalysts. The mesoporosity of the supports improved dispersion and access to the active sites and facilitated the diffusion of reactants and products during the

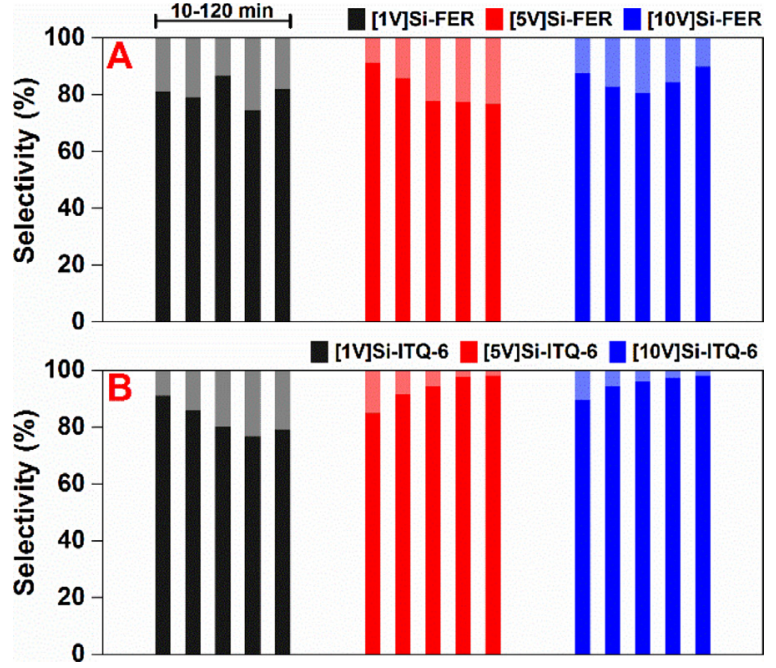

Fig. 8. Product selectivity using (A) the microporous vanadium catalysts and (B) the micro/mesoporous vanadium catalysts (dark colors represent the selectivity towards solketal and light colors represent the selectivity towards the 6-membered ring acetal).

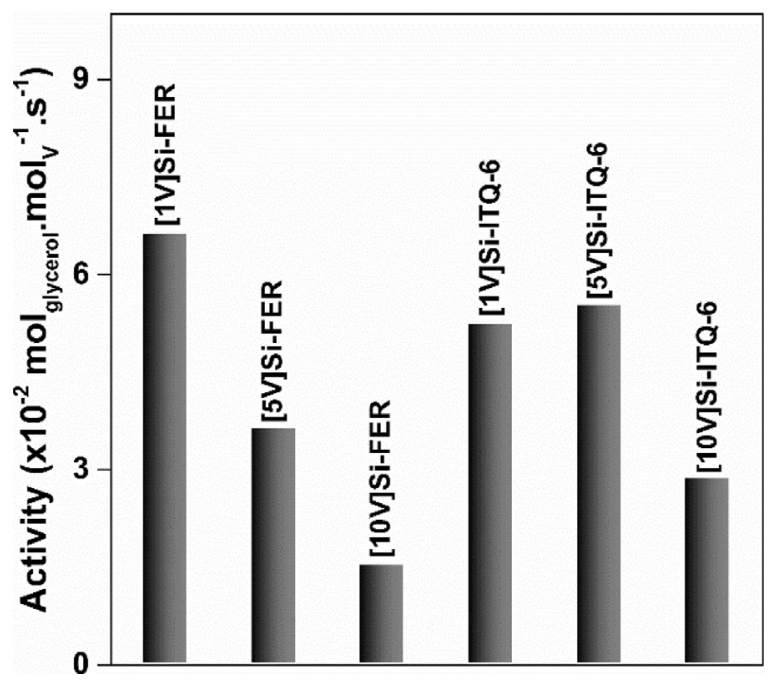

Fig. 9. Average activities of the catalysts after $60 \mathrm{~min}$ of reaction.
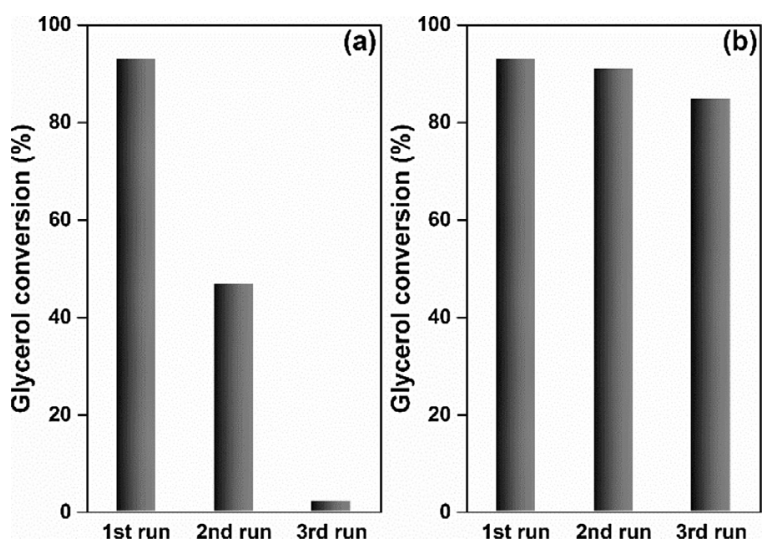

Fig. 10. Reusability of catalyst [10V]Si-ITQ-6. Conversions were measured after $1 \mathrm{~h}$ in each run. The catalyst was washed with (a) water or (b) acetone, after each run. 


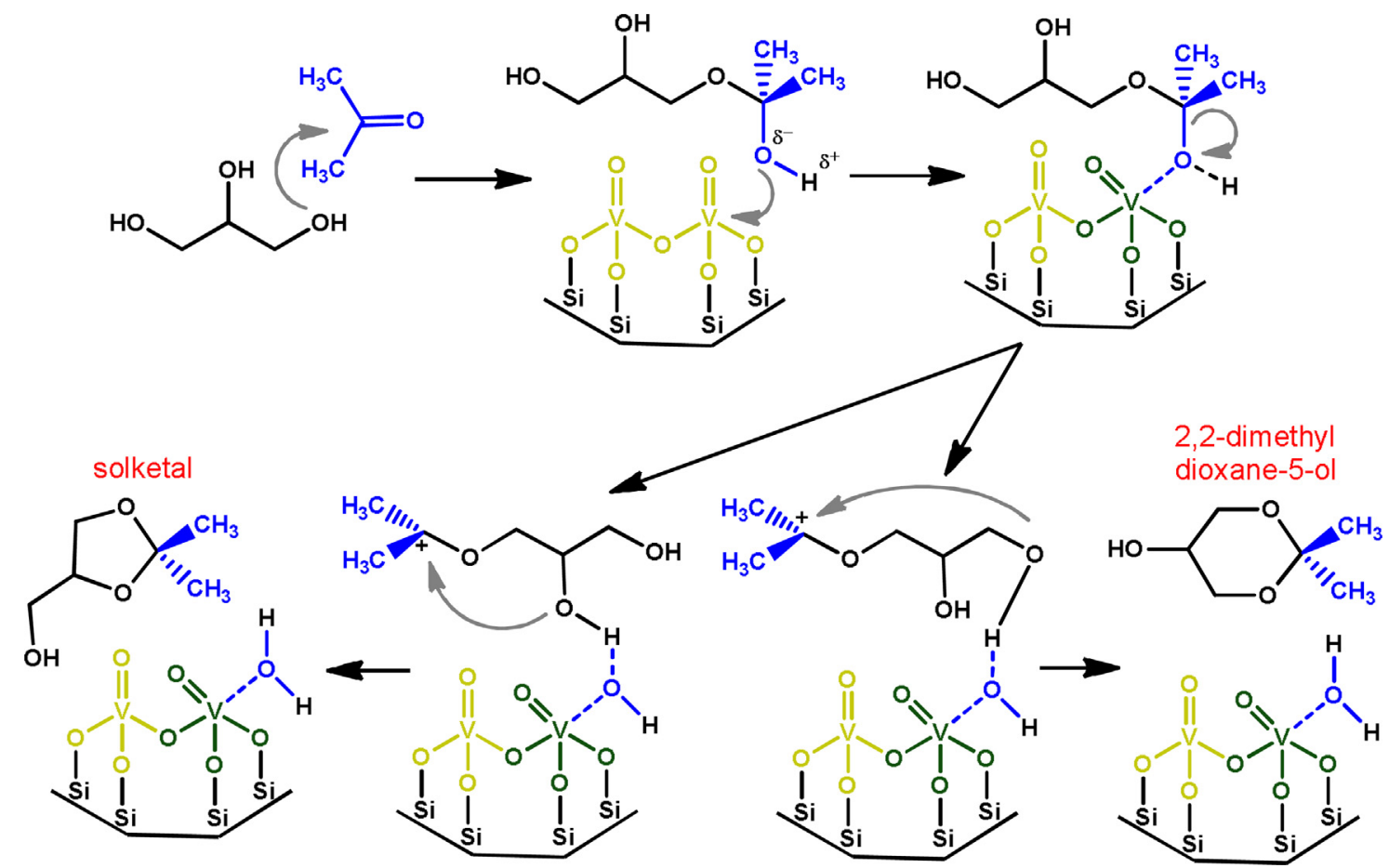

Scheme 4. Proposed mechanism for condensation of glycerol with acetone over [V]Si-FER and [V]Si-ITQ-6 catalysts.

reaction. The best catalyst, [5V]Si-ITQ-6, achieved $100 \%$ conversion after $2 \mathrm{~h}$ of reaction, with approximately $99 \%$ selectivity towards solketal.

This study showed that it was possible to obtain high solketal yields during the acetalization of acetone with glycerol, under mild reaction conditions and using moderate acidity vanadium catalysts. Exploitation of the structural properties of the materials improved dispersion of the active sites and facilitated diffusion and access during the reaction.

\section{Acknowledgements}

This work was supported by the Brazilian agencies FAPESP (grants \#2013/10204-2, \#2014/20116-6 and \#2016/10597-2) and CNPq (grant \#304698/2014-8). The authors also thank the Brazilian Synchrotron Light Laboratory (LNLS) in Campinas for use of the XPD (proposals XPD-18893 and XPD-20150244) and XAFS 1 (proposal 20150135) beamlines.

\section{Appendix A. Supplementary data}

Supplementary data associated with this article can be found, in the online version, at http://dx.doi.org/10.1016/j.mcat.2017.11. 027.

\section{References}

[1] A.R. Trifoi, P. Şerban, T. Agachi, Pap. Renew. Sustain. Energy Rev. 62 (2016) 804-814.

[2] M.R. Nanda, Y. Zhang, Z. Yuan, W. Qin, H.S. Ghaziaskar, C. Xu, Renew. Sustain. Energy Rev. 56 (2016) 1022-1031.

[3] B. Katryniok, S. Paul, F. Dumeignil, ACS Catal. 3 (2013) 1819-1834.

[4] L.G. Possato, R.N. Diniz, T. Garetto, S.H. Pulcinelli, C.V. Santilli, L. Martins, J. Catal. 300 (2013) 102-112.

[5] E. Tsukuda, S. Sato, R. Takahashi, T. Sodesawa, Catal. Commun. 8 (2007) 1349-1353.

[6] L.H. Vieira, K.T.G. Carvalho, E.A. Urquieta-González, S.H. Pulcinelli, C.V. Santilli, L. Martins, J. Mol. Catal. A Chem. 422 (2016) 148-157.

[7] M.V. Rodrigues, C. Vignatti, T. Garetto, S.H. Pulcinelli, C.V. Santilli, L. Martins, Appl. Catal. A Gen. 495 (2015) 84-91.
[8] S.H. Chai, H.P. Wang, Y. Liang, B.Q. Xu, Green Chem. 9 (2007) 1130-1136. [9] H. Atia, U. Armbruster, A. Martin, J. Catal. 258 (2008) 71-82.

[10] L.F. Rasteiro, L.H. Vieira, L.G. Possato, S.H. Pulcinelli, C.V. Santilli, L. Martins, Catal. Today 296 (2017) 10-18.

[11] L.G. Possato, W.H. Cassinelli, T. Garetto, S.H. Pulcinelli, C.V. Santilli, L. Martins, Appl. Catal. A Gen. 492 (2015) 243-251.

[12] L.G. Possato, W.H. Cassinelli, C.I. Meyer, T. Garetto, S.H. Pulcinelli, C.V. Santilli, L. Martins, Appl. Catal. A Gen. 532 (2017) 1-11.

[13] C. Liebig, S. Paul, B. Katryniok, C. Guillon, J.-L. Couturier, J.-L. Dubois, F. Dumeignil, W.F. Hoelderich, Appl. Catal. B Environ. 132 (2013) 170-182.

[14] M.O. Guerrero-Pérez, M.A. Bañares, ChemSusChem 1 (2008) 511-513.

[15] M.A. Dasari, P.-P. Kiatsimkul, W.R. Sutterlin, G.J. Suppes, Appl. Catal. A Gen. 281 (2005) 225-231.

[16] J. Chaminand, L. auren. Djakovitch, P. Gallezot, P. Marion, C. Pinel, C. Rosier, Green Chem. 6 (2004) 359.

[17] R. Mane, S. Patil, M. Shirai, S. Rayalu, C. Rode, Appl. Catal. B Environ. 204 (2017) 134-146

[18] S. García-Fernández, I. Gandarias, J. Requies, F. Soulimani, P.L. Arias, B.M. Weckhuysen, Appl. Catal. B Environ. 204 (2017) 260-272.

[19] J.A. Melero, G. Vicente, G. Morales, M. Paniagua, J.M. Moreno, R. Roldán, A. Ezquerro, C. Pérez, Appl. Catal. A Gen. 346 (2008) 44-51.

[20] F. Frusteri, F. Arena, G. Bonura, C. Cannilla, L. Spadaro, O. Di Blasi, Appl. Catal. A Gen. 367 (2009) 77-83.

[21] A.M. Ruppert, J.D. Meeldijk, B.W.M. Kuipers, B.H. Erné, B.M. Weckhuysen, Chem. - A Eur. J. 14 (2008) 2016-2024.

[22] M.-L. Tao, H.-Y. Guan, X.-H. Wang, Y.-C. Liu, R.-F. Louh, Fuel Process. Technol. 138 (2015) 355-360.

[23] X. Gao, S. Zhu, Y. Li, Catal. Commun. 62 (2015) 48-51.

[24] G. Dodekatos, H. Tüysüz, ChemCatChem 9 (2017) 610-619.

[25] X. Li, A.K. Tjiptoputro, J. Ding, J.M. Xue, Y. Zhu, Catal. Today 279 (2017) 77-83.

[26] M. Gonçalves, R. Rodrigues, T.S. Galhardo, W.A. Carvalho, Fuel 181 (2016) 46-54.

[27] J. Kowalska-Kus, A. Held, M. Frankowski, K. Nowinska, J. Mol. Catal. A Chem. 426 (2017) 205-212.

[28] D.C. de Carvalho, A.C. Oliveira, O.P. Ferreira, J.M. Filho, S. Tehuacanero-Cuapa, A.C. Oliveira, Chem. Eng. J. 313 (2017) 1454-1467.

[29] M.N. Timofeeva, V.N. Panchenko, V.V. Krupskaya, A. Gil, M.A. Vicente, Catal. Commun. 90 (2017) 65-69.

[30] V.R. Ruiz, A. Velty, L.L. Santos, A. Leyva-Pérez, M.J. Sabater, S. Iborra, A. Corma, J. Catal. 271 (2010) 351-357.

[31] R.P.V. Faria, C.S.M. Pereira, V.M.T.M. Silva, J.M. Loureiro, A.E. Rodrigues, Chem. Eng. J. 233 (2013) 159-167.

[32] P. Sudarsanam, B. Mallesham, A.N. Prasad, P.S. Reddy, B.M. Reddy, Fuel Process. Technol. 106 (2013) 539-545.

[33] M.B. Güemez, J. Requies, I. Agirre, P.L. Arias, V.L. Barrio, J.F. Cambra, Chem. Eng. J. 228 (2013) 300-307.

[34] H. Serafim, I.M. Fonseca, A.M. Ramos, J. Vital, J.E. Castanheiro, Chem. Eng. J 178 (2011) 291-296. 
[35] C.X.A. da Silva, C.J.A. Mota, Biomass Bioenergy 35 (2011) 3547-3551.

[36] M.R. Nanda, Y. Zhang, Z. Yuan, W. Qin, H.S. Ghaziaskar, C. Xu, Renew. Sustain Energy Rev. 56 (2016) 1022-1031.

[37] C.J.A. Mota, C.X.A. Da Silva, N. Rosenbach, J. Costa, F. Da Silva, Energy Fuels 24 (2010) 2733-2736.

[38] J. Deutsch, A. Martin, H. Lieske, J. Catal. 245 (2007) 428-435.

[39] P. Ferreira, I.M. Fonseca, A.M. Ramos, J. Vital, J.E. Castanheiro, Appl. Catal. B Environ. 98 (2010) 94-99.

[40] L. Li, T.I. Korányi, B.F. Sels, P.P. Pescarmona, Green Chem. 14 (2012) 1611.

[41] B. Solsona, J.M.L. Nieto, U. Diaz, Microporous Mesoporous Mater. 94 (2006) 339-347.

[42] V.V. Kaichev, Y.A. Chesalov, A.A. Saraev, A.Y. Klyushin, A. Knop-Gericke, T.V. Andrushkevich, V.I. Bukhtiyarov, J. Catal. 338 (2016) 82-93.

[43] F. Hatayama, T. Ohno, T. Maruoka, T. Ono, H. Miyata, J. Chem. Soc. Faraday Trans. 87 (1991) 2629.

[44] P.R. Hari Prasad Rao, A.V. Ramaswamy, P. Ratnasamy, J. Catal. 137 (1992) 225-231.

[45] R. Bulanek, L. Capek, M. Setnicka, P. Cicmanec, J. Phys. Chem. C 1243 (2011) 12430-12438.
[46] L. Schreyeck, P. Caullet, J.C. Mougenel, J.L. Guth, B. Marler, Microporous Mater 6 (1996) 259-271.

[47] A. Corma, U. Diaz, M.E. Domine, V. Fornes, J. Am. Chem. Soc. 122 (2000) 2804-2809.

[48] F.S.O. Ramos, M.K. de Pietre, H.O. Pastore, RSC Adv. 3 (2013) 2084-2111.

[49] W. Avansi, L.J.Q. Maia, C. Ribeiro, E.R. Leite, V.R. Mastelaro, J. Nanoparticle Res. 13 (2011) 4937-4946.

[50] J. Wong, F.W. Lytle, R.P. Messmer, D.H. Maylotte, Phys. Rev. B 30 (1984) 5596-5610.

[51] K. Inumaru, T. Okuhara, M. Misono, N. Matsubayashi, H. Shimada, A Nishijima, J. Chem. Soc. Faraday Trans. 88 (1992) 625

[52] K.L. Boyesen, F. Meneau, K. Mathisen, Phase Trans. 84 (2011) 675-686.

[53] K. Stawicka, A.E. Díaz-Álvarez, V. Calvino-Casilda, M. Trejda, M.A. Bañares, M. Ziolek, J. Phys. Chem. C 120 (2016) 16699-16711.

[54] L.P. Ozorio, R. Pianzolli, M.B.S. Mota, C.J.A. Mota, J. Braz. Chem. Soc. 23 (2012) 931-937. 